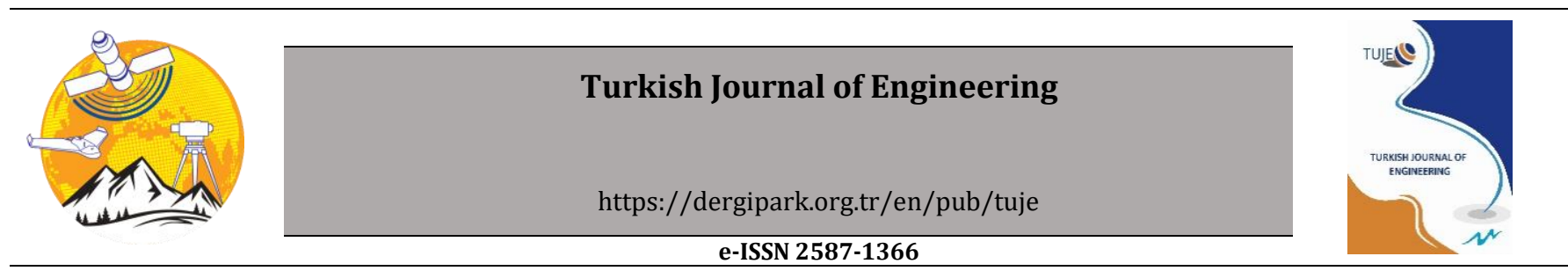

\title{
Optimal synthesis of function-generating slider-crank mechanism based on a closed-form solution using five design parameters
}

\author{
Hüseyin Mutlu*1, Ali Magdi Sayed Soliman¹, Gökhan Karapınarlı \\ ${ }_{1}^{1}$ Mersin University, Engineering Faculty, Mechanical Engineering Department, Mersin, Turkey \\ ${ }^{2}$ Akyürek Makine Sanayi ve Tic. A.Ş, Mersin, Turkey
}

\section{Keywords}

Kinematic Synthesis

Function Generation

Slider-Crank Mechanism

Closed-Form Solution

\begin{abstract}
Kinematic dimensional synthesis is one of the essential steps during the process of design. It is classified into three tasks: function generation, path generation, and motion generation. In this paper, a design method is presented to solve the synthesis of the slider-crank mechanism for function generation based on a closed-form solution with five design parameters. The success criterion of a method used for function generation depends on the structural error function within an operational domain of the slider-crank mechanism. The structural error reduction is related to the number of design parameters utilized in mechanism synthesis, and the effective maximum number of design parameters for the slider-crank mechanism is five. In this study, the closed-form synthesis is found using three methods: precision point method, sub-domain method, and galerkin method. The system of equations is reduced to a twelfthdegree univariate polynomial equation, and thus all the available solutions are obtained. The effectiveness of this design method is tested with some examples of commonly used test functions, namely $e^{x}, \sin (\mathrm{x}), \tan (\mathrm{x})$ and $\ln (\mathrm{x})$, using a developed computer program. This design method gives lower structural error than traditional methods in kinematics literature.
\end{abstract}

\section{INTRODUCTION}

In kinematic synthesis, the shape and size of mechanical elements are determined to develop a flow of power through the system between the input and the output links, according to the desired performance (McCarthy and Joskowicz 2009; Söylemez 1985). The motion equation of the output link is to be a function of the input link's motion or a function of time, and it is formed from nonlinear algebraic and/or high order equations (Dhingra et al. 2000a; Wampler et al. 1990; Wampler et al. 1992; Almadi et al. 1996; Dhingra et al. 2001a; Dhingra et al. 2000b; Dhingra et al. 2001b; Akçal 1984). These mathematical relationships between the input and output links are so complex; hence, graphical approaches are commonly utilized in solving such problems (Shigley 1961). However, graphical approaches are time-consuming and lack accuracy.

With the evolution of computers, many analytical methods have been developed, and they approximately express the desired function. Therefore, the structural error function which is the difference between the desired function and the function produced by a mechanism is taken into account and minimized using mathematical approaches depending on iteration such as the precision point method (Akçalı and Dittrich 1989), sub-domain method (Dhingra et al. 2000a), galerkin method (Hartenberg and Denavit 1964) and the leastsquares method (Nolle 1997; Singh et al. 2005). Here, the most important factor in minimizing the structural error is the excess number of unknown parameters of a mechanism.

However, since the aforementioned methods are based on iteration, the excess number of unknown parameters causes great difficulties, and thus the solution may be impossible. For instance, in the solution of the precision point method of synthesis applied to nine positions in reference (Almadi et al. 1995), the NewtonRaphson technique was used in a solution strategy called 'Bootstrap.' And, due to the complexity of the equation, 
the drawing for each initial value does not exist. Even if a solution exists, different results are obtained from different initial values.

For kinematic synthesis problems, the precision point method and the least-squares method are extensively used to minimize the structural error (Singh et al. 2005; Tinubu and Gupta 1984). In this way, the structural error is zero at the given precision points while, at the mean values, it is small as possible. When the number of precision points increases, the structural error decreases at the mean values. The number of points that can be selected depends on the number of kinematic dimensions of the active mechanism in the design. However, when the number of parameters used in the design increases, it becomes difficult to obtain a closedform solution. And if the number of unknown parameters exceeds five, the direct application of closed-form solutions to mechanism designs will probably lead to undesirable results (Akçalı 1984; Özkul and Mutlu 2018).

In this study, given five design parameters as a maximum, the design of the slider-crank mechanism for function generation with minimum error has been presented. The system of equations has been reduced to a twelfth-degree univariate polynomial equation, and in this way, all the possible solutions have been obtained. Because three methods (precision point method, subdomain method, and galerkin method) are used in the solution, the designer has been provided with alternative solutions. Additionally, the effectiveness of the presented mathematical model is tested on some commonly used test functions by using a developed computer program. Accordingly, we found that our design method gives lower structural error than traditional methods in kinematics literature.

\section{FUNCTION-GENERATING SLIDER-CRANK MECHANISM}

For creating a required function using the slidingcrank mechanism, first, Fig. 1, which shows the mechanism's design parameters, is given. Here, $x_{1}$ is the crank length, $x_{2}$ is the connecting rod length, and $x_{3}$ is the vertical distance $\left(\mathrm{AO}_{1}\right) \cdot \psi_{0}$ is the angle when the crank starts rotating and $s_{n}$ is the distance (AC), vertical on the $\mathrm{AO}_{1}$ line, at the starting position when the angle $\psi_{0}$ occurs. While designing a function-generating slidercrank mechanism, two different functional relationships can be considered. The first functional relationship is between the crank rotation angle $(\psi)$ and the linear horizontal displacement of the piston (s). The second functional relationship is between the crank rotation angle $(\psi)$ and the angle of the connecting rod with the horizontal line $(\delta)$.

If the $\psi$-s functional relation is taken into consideration, the vector expression written from the closed-loop $\mathrm{AO}_{1} \mathrm{BC}$ in Fig. 1 is squared and added side by side, and the angle of the connecting rod with the horizontal line $(\delta)$ is eliminated, the following motion equation, Eq. (1), is generated.

$$
\mathrm{x}_{1}^{2}-2 \mathrm{sx}_{1} \operatorname{Cos} \psi+2 \mathrm{x}_{1} \mathrm{x}_{3} \operatorname{Sin} \psi+\mathrm{x}_{3}^{2}+\mathrm{s}^{2}-\mathrm{x}_{2}^{2}=0
$$

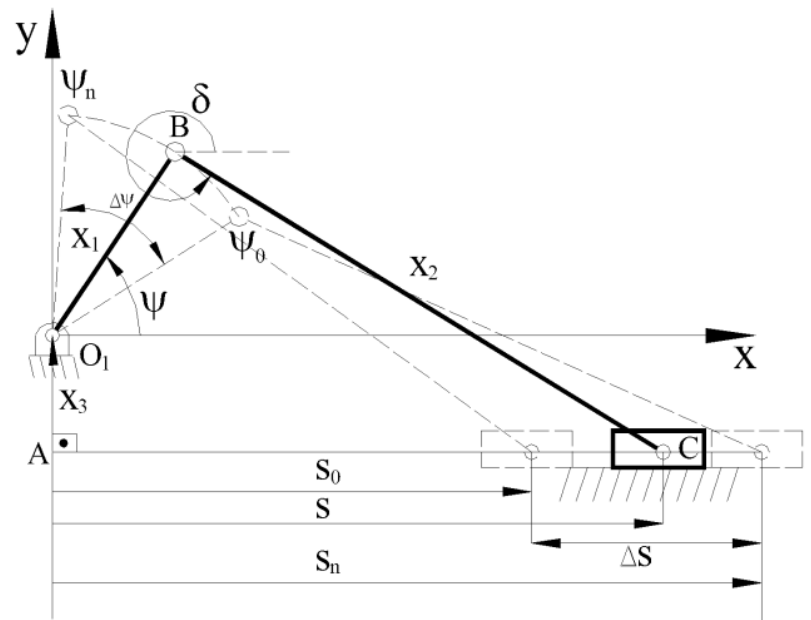

Figure 1. The design parameters of a functiongenerating slider-crank mechanism

Also, the following linear relations of the slider-crank mechanism, the angle $(\psi)$ with the independent variable (x) of the desired function and the piston displacement (s) with the function's dependent variable (y), can be established as in expressions (2) and (3), respectively.

$$
\begin{gathered}
\psi=\psi_{0}+\psi^{\prime} \\
\psi^{\prime}=R_{x}\left(x-x_{0}\right) \\
R_{x}=\frac{\Delta \psi}{\Delta x} \\
s=s_{0}+s^{\prime} \\
s^{\prime}=R_{y}\left(y-y_{0}\right) \\
R_{y}=\frac{\Delta s}{\Delta y}
\end{gathered}
$$

Here, the operational domains of the crank link and piston, determined by the designer, $\operatorname{are}\left(\Delta \psi=\psi_{n}-\right.$ $\left.\psi_{0}\right)$ and $\left(\Delta s=s_{n}-s_{0}\right)$, respectively. Also, the change amounts of the independent variable and dependent variable of the generated function are $\left(\Delta x=x_{n}-x_{0}\right)$ and $\left(\Delta y=y_{n}-y_{0}\right)$, respectively. If Eq. (2) and Eq. (3) are written in Eq. (1), the motion equation can be obtained in the shape of $\mathrm{G}\left(s_{0}, \psi_{0}, x_{1}, x_{2}, x_{3}, x, y\right)=0$ as shown in Eq. (4).

$$
\begin{aligned}
2 s^{\prime} s_{0}+s^{\prime 2}+Z_{3} & \left(\sin \psi_{0} \cos \psi^{\prime}+\cos \psi_{0} \sin \psi^{\prime}\right) \\
& +Z_{1}\left(-s_{0} \cos \psi_{0} \cos \psi^{\prime}\right. \\
& +s_{0} \sin \psi_{0} \sin \psi^{\prime} \\
& -s^{\prime} \cos \psi_{0} \cos \psi^{\prime} \\
& \left.+s^{\prime} \sin \psi_{0} \sin \psi^{\prime}\right)+Z_{2}=0
\end{aligned}
$$

where,

$$
\begin{aligned}
& Z_{1}=2 x_{1} \\
& Z_{2}=x_{1}{ }^{2}+x_{3}{ }^{2}+s_{0}{ }^{2}-x_{2}{ }^{2} \\
& Z_{3}=2 x_{1} x_{3}
\end{aligned}
$$

For solving the unknown parameters $\left(s_{0}, \psi_{0}, x_{1}, x_{2}, x_{3}\right)$ in Eq. (4), a nonlinear equation with five unknowns is obtained as shown in Eq. (5). 


$$
\begin{aligned}
\left(a_{i} s_{0}+g_{i}\right)+Z_{3} & \left(c_{i} \operatorname{Sin} \psi_{0}+b_{i} \operatorname{Cos} \psi_{0}\right) \\
& +Z_{1}\left(-c_{i} s_{0} \operatorname{Cos} \psi_{0}+b_{i} s_{0} \operatorname{Sin} \psi_{0}\right. \\
& -d_{i} \operatorname{Cos} \psi_{0}+e_{i} \operatorname{Sin} \psi_{0}+f_{i} Z_{2} \\
& =0 i=1,2,3,4,5
\end{aligned}
$$

The coefficients $\left(a_{i}, b_{i}, c_{i}, d_{i}, e_{i}, f_{i}, g_{i}\right)$ in Eq.(5) can be solved using the three methods: precision point method, sub-domain method, and galerkin method.

\section{Precision Point Method:}

$$
\begin{gathered}
a_{i}=2 s_{i}^{\prime} \\
b_{i}=\operatorname{Sin} \psi_{i}^{\prime} \\
c_{i}=\operatorname{Cos} \psi_{i}^{\prime} \\
d_{i}=s^{\prime} \operatorname{Cos} \psi_{i}^{\prime} \\
e_{i}=s_{i}^{\prime} \operatorname{Sin} \psi_{0}^{\prime} \\
f_{i}=1 \\
g_{i}=s^{\prime}{ }_{i}^{2} \\
i=1,2,3,4,5
\end{gathered}
$$

\section{Sub-domain Method:}

$a_{i}=2 \int_{x_{i-1}}^{x_{i}} s^{\prime} d x$

$b_{i}=\int_{x_{i-1}}^{x_{i}} \operatorname{Sin} \psi^{\prime} d x$

$c_{i}=\int_{x_{i-1}}^{x_{i}} \operatorname{Cos} \psi^{\prime} d x$

$\left.d_{i}=\int_{x_{i-1}}^{x_{i}} s^{\prime} \operatorname{Cos} \psi^{\prime} d x\right\} i=1,2,3,4,5$

$e_{i}=\int_{x_{i-1}}^{x_{i}} s^{\prime} \operatorname{Sin} \psi^{\prime} d x$

$f_{i}=\int_{x_{i-1}}^{x_{i}} d x$

$g_{i}=\int_{x_{i-1}}^{x_{i}} s^{\prime 2} d x \quad$

\section{Galerkin Method:}

$a_{i}=2 \int_{x_{0}}^{x_{n}} s^{\prime} w_{i}(x) d x$

$b_{i}=\int_{x_{0}}^{x_{n}} \operatorname{Sin} \psi^{\prime} w_{i}(x) d x$

$c_{i}=\int_{x_{0}}^{x_{n}} \operatorname{Cos} \psi^{\prime} w_{i}(x) d x$

$\left.d_{i}=\int_{x_{0}}^{x_{n}} s^{\prime} \operatorname{Cos} \psi^{\prime} w_{i}(x) d x\right\} i=1,2,3,4,5$

$e_{i}=\int_{x_{0}}^{x_{n}} s^{\prime} \operatorname{Sin} \psi^{\prime} w_{i}(x) d x$

$f_{i}=\int_{x_{0}}^{x_{n}} w_{i}(x) d x$

$g_{i}=\int_{x_{0}}^{x_{n}} s^{\prime 2} w_{i}(x) d x$

To achieve the closed-form solution, if $Z_{2}, Z_{3}$ and $\mathrm{Z}_{1}$ are eliminated from Eq. (5) and the equation is rearranged, two nonlinear equations depending on the unknown parameters $\tan \left(\psi_{0}\right)$ and $s_{0}$ are obtained, as in Eq. (9).

$$
\begin{gathered}
a_{p k} s_{0}^{2}+\left(b_{p k}+c_{p k} \cos 2 \psi_{0}+d_{p k} \sin 2 \psi_{0}\right) s_{0} \\
+e_{p k}+f_{p k} \cos 2 \psi_{0} \\
\left.+g_{p k} \sin 2 \psi_{0}\right)=0 \\
k=1,2
\end{gathered}
$$

The computable coefficients in Eq. (9) are given below in Appendix A in Eqs. (10-16). If the term ( $\left.\mathrm{s}_{0}\right)$ is removed using the intersection function mentioned in
(Akçalı et al. 2006), the 12th-degree univariate polynomial equation dependent on $t$ can be obtained as in Eq. (17).

$$
\begin{aligned}
& \begin{array}{l}
\mathrm{w}_{0}+\mathrm{w}_{1} \mathrm{t}+\mathrm{w}_{2} \mathrm{t}^{2}+\mathrm{w}_{3} \mathrm{t}^{3}+\mathrm{w}_{4} \mathrm{t}^{4}+\mathrm{w}_{5} \mathrm{t}^{5} \\
+\mathrm{w}_{6} \mathrm{t}^{6}-\mathrm{w}_{5} \mathrm{t}^{7}+\mathrm{w}_{4} \mathrm{t}^{8}-\mathrm{w}_{3} \mathrm{t}^{9} \\
+\mathrm{w}_{2} \mathrm{t}^{10}-\mathrm{w}_{1} \mathrm{t}^{11}+\mathrm{w}_{0} \mathrm{t}^{12}=0
\end{array} \\
& \text { where, } \mathrm{t}=\tan \frac{\psi_{0}}{2}
\end{aligned}
$$

The coefficients of Eq. (17) are given also in Appendix A in Eqs. (19-25). As a result of finding all the roots of Eq. (17), a set of 12 solutions (real or complex) for the $\psi_{0}$ angle is found as given in Eq. (26).

$$
\psi_{o i}=2 \arctan t_{i} ; i=1,2 \ldots, 12
$$

For calculating the other kinematic quantities $\left(\mathrm{s}_{0}, \mathrm{x}_{1}\right.$, $\left.\mathrm{x}_{2}, \mathrm{x}_{3}\right)$ of the function-generating slider-crank mechanism, firstly, if the term $\mathrm{S}_{0}^{2}$ is removed from Eq. (9), so will be found as in Eq. (27).

$$
\begin{aligned}
& a_{p 1} e_{p 2}-a_{p 2} e_{p 1}+ \\
& \left(a_{p 1} f_{p 2}-a_{p 2} f_{p 1}\right) \cos 2 \psi_{0 i}+ \\
s_{o i}=- & \frac{\left(a_{p 1} g_{p 2}-a_{p 2} g_{p 1}\right) \sin 2 \psi_{0 i}}{a_{p 1} b_{p 2}-a_{p 2} b_{p 1}+} \\
& \left(a_{p 1} c_{p 2}-a_{p 2} c_{p 1}\right) \cos 2 \psi_{0 i}+ \\
& \left(a_{p 1} d_{p 2}-a_{p 2} d_{p 1}\right) \sin 2 \psi_{0 i}
\end{aligned}
$$$$
i=1, \ldots, 12
$$

And, for calculating the other three dimensional parameters $\left(\mathrm{x}_{1}, \mathrm{x}_{2}\right.$ and $\left.\mathrm{x}_{3}\right)$, the following path in Eqs. (2833) is followed.

$$
\begin{aligned}
& 2 \cos \psi_{0 i}\left(-d_{k} f_{2} g_{1}+d_{2} f_{k} g_{1}+d_{k} f_{1} g_{2}-\right. \\
& \left.d_{1} f_{k} g_{2}-d_{2} f_{1} g_{k}+d_{1} f_{2} g_{k}\right)+ \\
& 2 \sin \psi_{0 i}\left(e_{k} f_{2} g_{1}-e_{2} f_{k} g_{1}-e_{k} f_{1} g_{2}+\right. \\
& \left.e_{1} f_{k} g_{2}+e_{2} f_{1} g_{k}-e_{1} f_{2} g_{k}\right)+ \\
& s_{0}\left(2 \operatorname { s i n } \psi _ { 0 i } \left(a_{k} e_{2} f_{1}-a_{2} e_{k} f_{1}-a_{k} e_{1} f_{2}+\right.\right. \\
& a_{1} e_{k} f_{2}+a_{2} e_{1} f_{k}-a_{1} e_{2} f_{k}+ \\
& b_{k} f_{2} g_{1}-b_{2} f_{k} g_{1}-b_{k} f_{1} g_{2}+b_{1} f_{k} g_{2}+ \\
& \left.b_{2} f_{1} g_{k}-b_{1} f_{2} g_{k}\right)+ \\
& 2 \cos \psi_{0 i}\left(-a_{k} d_{2} f_{1}+a_{2} d_{k} f_{1}+a_{k} d_{1} f_{2}-\right. \\
& a_{1} d_{k} f_{2}-a_{2} d_{1} f_{k}+a_{1} d_{2} f_{k}- \\
& c_{k} f_{2} g_{1}+c_{2} f_{k} g_{1}+c_{k} f_{1} g_{2}-c_{1} f_{k} g_{2}- \\
& \left.\left.c_{2} f_{1} g_{k}+c_{1} f_{2} g_{k}\right)\right)+ \\
& s_{0}^{2}\left(2 \operatorname { s i n } \psi _ { 0 i } \left(a_{k} b_{2} f_{1}-a_{2} b_{k} f_{1}-a_{k} b_{1} f_{2}+\right.\right. \\
& \left.a_{1} b_{k} f_{2}+a_{2} b_{1} f_{k}-a_{1} b_{2} f_{k}\right)+ \\
& 2 \cos \psi_{0 i}\left(-a_{k} c_{2} f_{1}+a_{2} c_{k} f_{1}+a_{k} c_{1} f_{2}-\right. \\
& Z_{3 i}=-\frac{\left(\begin{array}{l}
2 \cos f_{0 i}\left(-a_{k} c_{2} f_{1}+a_{2} c_{k} f_{1}+a_{k} c_{1} f_{2}-\right. \\
\left.\left.a_{1} c_{k} f_{2}-a_{2} c_{1} f_{k}+a_{1} c_{2} f_{k}\right)\right)+
\end{array}\right.}{\left\{\begin{array}{l}
-b_{k} d_{2} f_{1}+b_{2} d_{k} f_{1}+c_{k} e_{2} f_{1}-c_{2} e_{k} f_{1}+ \\
b_{k} d_{1} f_{2}-b_{1} d_{k} f_{2}-c_{k} e_{1} f_{2}+ \\
c_{1} e_{k} f_{2}-b_{2} d_{1} f_{k}+b_{1} d_{2} f_{k}+c_{2} e_{1} f_{k}-c_{1} e_{2} f_{k}+ \\
\sin 2 \psi_{0 i}\left(-c_{k} d_{2} f_{1}+c_{2} d_{k} f_{1}+b_{k} e_{2} f_{1}-\right. \\
b_{2} e_{k} f_{1}+c_{k} d_{1} f_{2}-c_{1} d_{k} f_{2}-b_{k} e_{1} f_{2}+ \\
\left.b_{1} e_{k} f_{2}-c_{2} d_{1} f_{k}+c_{1} d_{2} f_{k}+b_{2} e_{1} f_{k}-b_{1} e_{2} f_{k}\right)+ \\
\cos 2 \psi_{0 i}\left(-b_{k} d_{2} f_{1}+b_{2} d_{k} f_{1}-c_{k} e_{2} f_{1}+\right. \\
c_{2} e_{k} f_{1}+b_{k} d_{1} f_{2}-b_{1} d_{k} f_{2}+c_{k} e_{1} f_{2}- \\
\left.c_{1} e_{k} f_{2}-b_{2} d_{1} f_{k}+b_{1} d_{2} f_{k}-c_{2} e_{1} f_{k}+c_{1} e_{2} f_{k}\right)+ \\
2 s_{0 i}\left(-b_{k} c_{2} f_{1}+b_{2} c_{k} f_{1}+b_{k} c_{1} f_{2}-\right. \\
\left.b_{1} c_{k} f_{2}-b_{2} c_{1} f_{k}+b_{1} c_{2} f_{k}\right)
\end{array}\right\}} \\
& i=1, \ldots, 12 \\
& k=3,4,5
\end{aligned}
$$




$$
\begin{gathered}
Z_{1 i}=-\frac{\left\{\begin{array}{l}
f_{1} g_{k}-f_{k} g_{1}+s_{0 i}\left(a_{k} f_{1}-a_{1} f_{k}\right)+ \\
Z_{3 i} \cos \psi_{0 i}\left(b_{k} f_{1}-b_{1} f_{k}\right)+ \\
z_{3 i} \sin \psi_{0 i}\left(c_{k} f_{1}-c_{1} f_{k}\right)
\end{array}\right\}}{\left\{\begin{array}{l}
\cos \psi_{0 i}\left(s_{0 i}\left(c_{1} f_{k}-c_{k} f_{1}\right)+\right. \\
\left.d_{1} f_{k}-d_{k} f_{1}\right)+ \\
\sin \psi_{0 i}\left(s_{0 i}\left(b_{k} f_{1}-b_{1} f_{k}\right)+\right. \\
\left.e_{k} f_{1}-e_{1} f_{k}\right)
\end{array}\right\}} \\
\begin{array}{c}
i=1, \ldots, 12 \\
k=1,2,3,4,5
\end{array} \\
x_{1 i}=\frac{Z_{1 i}}{2} \quad i=1,2, \ldots, 12 \\
x_{3 i}=\frac{Z_{3 i}}{2 x_{1 i}} \quad i=1,2, \ldots, 12 \\
\sqrt{x_{1 i}^{2}+x_{3 i}^{2}+s_{0 i}^{2}-Z_{2 i}} \quad i=1,2, \ldots, 12
\end{gathered}
$$

The structural error (e) is given in Eq. (34) to determine the accuracy of the actual solutions $\left(\mathrm{x}_{1 \mathrm{j}}, \mathrm{x}_{2 \mathrm{j}}, \mathrm{X}_{3} \mathrm{j}\right.$, $\left.\mathrm{S}_{0 \mathrm{j}}, \psi_{0 \mathrm{j}}\right), \mathrm{j}=1,2, \ldots, 12$, in the solution set.

$$
e=s_{t h}-s_{a c}
$$

where $S_{\text {th }}$ is the theoretical piston displacement calculated in Eq. (3), and Sac represents the actual piston displacement calculated from Eq. (35) below. Finally only one solution from Eq. (35) will correspond to the desired function.

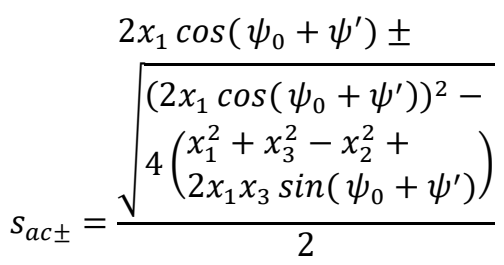

The compatibility of the designed slider-crank mechanism to the desired function is determined by the distribution of the structural error function in Eq. (34).

\section{NUMERICAL EXAMPLES}

The above-mentioned design approaches were employed using a developed computer program for generating commonly used functions such as $e^{x}, \sin (\mathrm{x})$, $\tan (\mathrm{x})$, and $\ln (\mathrm{x})$ by the slider-crank mechanism. Taking into consideration the structural error values of the real solutions from among the various solutions obtained as well as the compatibility of the aspect ratios with manufacturing, the structural error functions of the three approaches are presented. Here, four examples of test functions generated by the slider-crank mechanism are given.

\subsection{Example A}

In this example, the desired function is $y=\mathrm{e}^{\mathrm{x}}$ over

\begin{tabular}{|c|c|}
\hline \multicolumn{2}{|l|}{ Precision Point Method } \\
\hline Precision points & $\begin{array}{l}\text { Xpi, }(i=1, \ldots, 5)=0.0,0.2 \text {, } \\
0.5,0.8,1.0\end{array}$ \\
\hline \multirow[t]{5}{*}{ Mechanism dimensions } & $\mathrm{x}_{1}=-1.241043$ \\
\hline & $\mathrm{x}_{2}=2.123150$ \\
\hline & $x_{3}=-0.814295$ \\
\hline & $\psi_{0}=150.324^{\circ}$ \\
\hline & $s_{0}=-0.492244$ \\
\hline Maximum absolute error & 0.00027071 \\
\hline \multicolumn{2}{|l|}{ Sub-domain Method } \\
\hline Sub-domains & $\begin{array}{l}\mathrm{X}_{\mathrm{si}},(\mathrm{i}=1, \ldots, 6)=0.0,0.2 \\
0.4,0.6,0.8,1.0\end{array}$ \\
\hline \multirow[t]{5}{*}{ Mechanism dimensions } & $\mathrm{x}_{1}=-1.223522$ \\
\hline & $\mathrm{x}_{2}=2.119717$ \\
\hline & $x_{3}=-0.820609$ \\
\hline & $\psi_{0}=150.6590^{\circ}$ \\
\hline & $S_{0}=-0.506569$ \\
\hline Maximum absolute error & -0.00069492 \\
\hline \multicolumn{2}{|l|}{ Galerkin Method } \\
\hline Weighting functions & $\begin{array}{l}\mathrm{W}_{\mathrm{i}},(\mathrm{i}=1, \ldots, 5)=1, \mathrm{x}, \mathrm{x}^{2}, \mathrm{x}^{3}, \\
\mathrm{x}^{4}\end{array}$ \\
\hline \multirow[t]{5}{*}{ Mechanism dimensions } & $\mathrm{x}_{1}=-1.240452$ \\
\hline & $\mathrm{x}_{2}=2.137685$ \\
\hline & $\mathrm{X}_{3}=-0.824552$ \\
\hline & $\psi_{0}=149.7941^{\circ}$ \\
\hline & $S_{0}=-0.499602$ \\
\hline Maximum absolute error & -0.00037269 \\
\hline
\end{tabular}
$0 \leq x \leq 1$. The design results of the slider-crank mechanism that produces this function while the input link rotates $\Delta \psi=90^{\circ}$ and the output link moves $\Delta s=-1.0$ (dimensionless, as a scale) have been obtained according to the three different methods as shown in Table 1.
Table 1. The design results for $y=e^{x}$ over $0 \leq x \leq 1$ using three methods

The structural error distribution for this example is shown in Fig. (2).

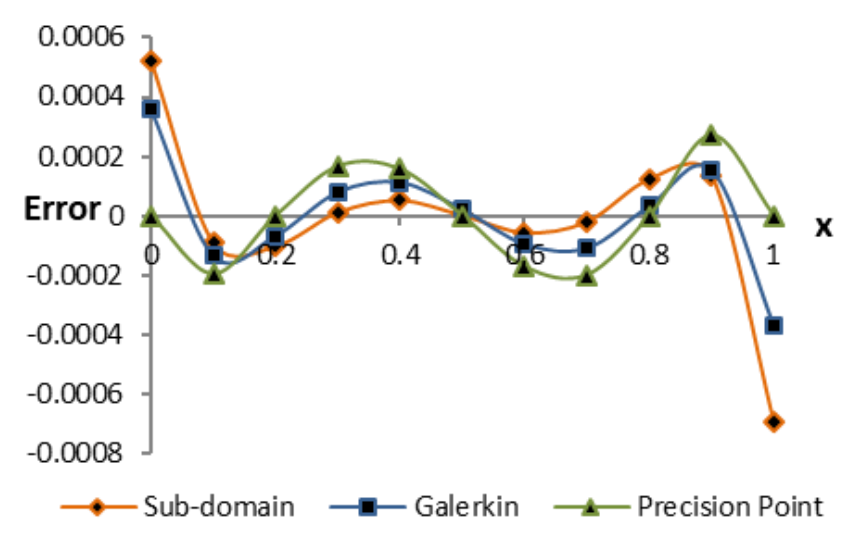

Figure 2. Structural error curve for $e^{x}$

\subsection{Example B}

The desired function of this example is $y=\sin (x)$ over $0^{\circ} \leq \mathrm{x} \leq 90^{\circ}$. The design results of the slider-crank mechanism that produces this function while the input link rotates $\Delta \psi=80^{\circ}$ and the output link moves $\Delta \mathrm{s}=$ -1.0 have been obtained according to the three different methods as shown in Table 2 .

The structural error distribution for this example is as shown in Fig. (3). 
Table 2. The design results for $y=\sin (x)$ over $0^{\circ} \leq x \leq$ $90^{\circ}$ using three methods

\begin{tabular}{|c|c|}
\hline \multicolumn{2}{|l|}{ Precision Point Method } \\
\hline Precision points & $\begin{array}{l}\mathrm{Xpi},(\mathrm{i}=1, \ldots, 5)=0.000 \\
0.436,0.873,1.309,1.571\end{array}$ \\
\hline \multirow[t]{5}{*}{ Mechanism dimensions } & $\mathrm{x}_{1}=-1.086305$ \\
\hline & $\mathrm{x}_{2}=7.310604$ \\
\hline & $\mathrm{X}_{3}=0.917419$ \\
\hline & $\psi_{0}=-73.7607^{\circ}$ \\
\hline & $s_{0}=-7.346641$ \\
\hline Maximum absolute error & -0.00014533 \\
\hline \multicolumn{2}{|l|}{ Sub-domain Method } \\
\hline Sub-domains & $\begin{array}{l}\mathrm{X}_{\mathrm{si}},(\mathrm{i}=1, \ldots, 6)=0.000 \\
0.349, \quad 0.698, \\
1.396,1.571\end{array}$ \\
\hline \multirow[t]{5}{*}{ Mechanism dimensions } & $\mathrm{x}_{1}=-1.088700$ \\
\hline & $\mathrm{x}_{2}=7.504273$ \\
\hline & $\mathrm{x}_{3}=0.941629$ \\
\hline & $\psi_{0}=-73.7607^{\circ}$ \\
\hline & $s_{0}=-7.541173$ \\
\hline Maximum absolute error & 0.00025793 \\
\hline \multicolumn{2}{|l|}{ Galerkin Method } \\
\hline Weighting functions & $\begin{array}{l}w_{i},(i=1, \ldots, 5)=1, x, x^{2}, x^{3}, \\
x^{4}\end{array}$ \\
\hline \multirow[t]{5}{*}{ Mechanism dimensions } & $\mathrm{x}_{1}=-1.077320$ \\
\hline & $\mathrm{x}_{2}=7.185135$ \\
\hline & $\mathrm{X}_{3}=1.089057$ \\
\hline & $\psi_{0}=-72.5057^{\circ}$ \\
\hline & $S_{0}=-7.190281$ \\
\hline Maximum absolute error & -0.00010383 \\
\hline
\end{tabular}

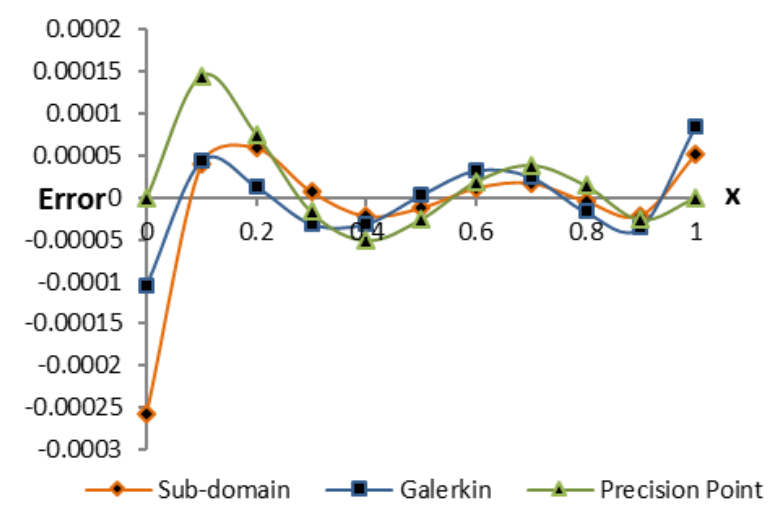

Figure 3. Structural error curve for $\sin (x)$

\subsection{Example C}

In this example, the desired function is $\mathrm{y}=\tan (\mathrm{x})$ over $0^{\circ} \leq \mathrm{x} \leq 45^{\circ}$. The design results of the slider-crank mechanism that produces this function while the input link rotates $\Delta \psi=80^{\circ}$ and the output link moves $\Delta s=$ -0.5 have been obtained according to the three different methods as shown below in Table 3.

The structural error distribution for this example is as shown in Fig. (4).
Table 3. The design results for $y=\tan (x)$ over $0^{\circ} \leq x \leq$ $45^{\circ}$ using three methods

\begin{tabular}{ll}
\hline Precision Point Method & \\
\hline Precision points & $\mathrm{X}_{\mathrm{pi}},(\mathrm{i}=1, \ldots, 5)=0.000$, \\
Mechanism dimensions & $\mathrm{X}_{1}=3.002218$ \\
& $\mathrm{X}_{2}=2.470431$ \\
& $\mathrm{X}_{3}=-0.531810$ \\
& $\Psi_{0}=92.8363^{\circ}$ \\
& $\mathrm{S}_{0}=-0.013371$ \\
Maximum absolute error & -0.00011431 \\
\hline Sub-domain Method & \\
\hline Sub-domains & $\mathrm{X}_{\mathrm{si}},(\mathrm{i}=1, \ldots, 6)=0.000$, \\
& $0.175,0.349,0.524$, \\
& $0.698,0.785$ \\
Mechanism dimensions & $\mathrm{X}_{1}=3.458880$ \\
& $\mathrm{X}_{2}=2.928213$ \\
& $\mathrm{X}_{3}=-0.530865$ \\
& $\Psi_{0}=94.2682^{\circ}$ \\
Maximum absolute error & $\mathrm{S}_{0}=-0.019198$ \\
-0.00102642 \\
\hline Galerkin Method & \\
\hline Weighting functions & $\mathrm{W}_{\mathrm{i}},(\mathrm{i}=1, \ldots, 5)=1, \mathrm{x}, \mathrm{x}^{2}, \mathrm{x}^{3}$, \\
& $\mathrm{X}^{4}$ \\
Mechanism dimensions & $\mathrm{X}_{1}=3.278928$ \\
& $\mathrm{X}_{2}=2.747495$ \\
& $\mathrm{X}_{3}=-0.531536$ \\
& $\Psi_{0}=93.7131^{\circ}$ \\
& $\mathrm{S}_{0}=-0.017070$ \\
& -0.00053734 \\
\hline & \\
\hline &
\end{tabular}

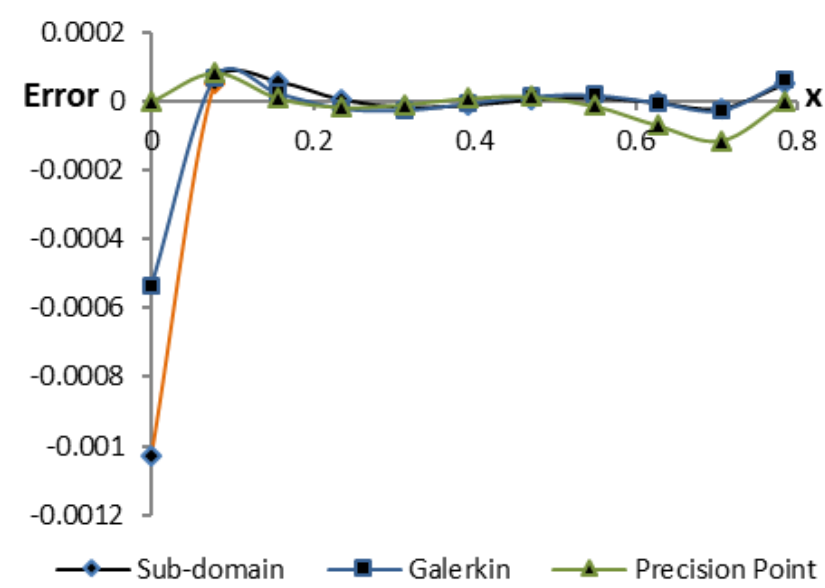

Figure 4. Structural error curve for $\tan (x)$

\subsection{Example D}

Finally, in this example, the desired function is $y=\ln (x)$ over $1 \leq x \leq 2$. The design results of the slider-crank mechanism that produces this function while the input link rotates $\Delta \psi=90^{\circ}$ and the output link moves $\Delta s=$ -0.1 have been obtained according to the following three different methods shown in Table 4.

The structural error distribution for this example is as shown in Fig. (5). 
Table 4. The design results for $y=\ln (x)$ over $1 \leq x \leq 2$ using three methods

\begin{tabular}{|c|c|}
\hline \multicolumn{2}{|l|}{ Precision Point Method } \\
\hline Precision points & $\begin{array}{l}\mathrm{Xpi},(\mathrm{i}=1, \ldots, 5)=1.00,1.20 \\
1.50,1.80,2.00\end{array}$ \\
\hline \multirow[t]{5}{*}{ Mechanism dimensions } & $\mathrm{x}_{1}=1.505762$ \\
\hline & $\mathrm{x}_{2}=2.608397$ \\
\hline & $x_{3}=-1.094561$ \\
\hline & $\psi_{0}=151.2138^{\circ}$ \\
\hline & $\mathrm{S}_{0}=1.262414$ \\
\hline Maximum absolute error & 0.00025632 \\
\hline \multicolumn{2}{|l|}{ Sub-domain Method } \\
\hline Sub-domains & $\begin{array}{l}\mathrm{X}_{\mathrm{si}}, \quad(\mathrm{i}=1, \ldots, 6)=1.00 \\
1.200,1.40,1.60,1.80 \\
2.00\end{array}$ \\
\hline \multirow[t]{5}{*}{ Mechanism dimensions } & $\mathrm{x}_{1}=1.475092$ \\
\hline & $\mathrm{x}_{2}=2.590246$ \\
\hline & $\mathrm{x}_{3}=-1.105152$ \\
\hline & $\psi_{0}=151.1454^{\circ}$ \\
\hline & $\mathrm{s}_{0}=1.268790$ \\
\hline Maximum absolute error & -0.00080016 \\
\hline \multicolumn{2}{|l|}{ Galerkin Method } \\
\hline Weighting functions & $\begin{array}{l}\mathrm{W}_{i},(\mathrm{i}=1, \ldots, 5)=1, x, x^{2}, x^{3}, \\
x^{4}\end{array}$ \\
\hline \multirow[t]{5}{*}{ Mechanism dimensions } & $x_{1}=1.507783$ \\
\hline & $x_{2}=2.620459$ \\
\hline & $x_{3}=-1.103462$ \\
\hline & $\psi_{0}=151.8690^{\circ}$ \\
\hline & $\mathrm{s}_{0}=1.261505$ \\
\hline Maximum absolute error & -0.00055926 \\
\hline
\end{tabular}

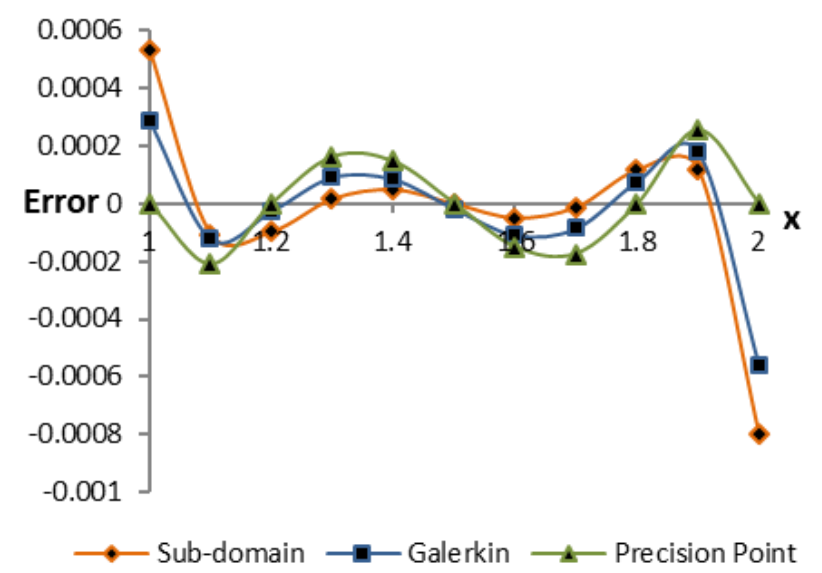

Figure 5. Structural error curve for $\ln (x)$

\section{DISCUSSION AND CONCLUSION}

During the examination of the abovementioned examples, the achieved maximum values in the structural error distributions of the three methods (precision point method, sub-domain method, and galerkin method) are compared with the results discussed in kinematics literature as given in Appendix B. Accordingly, our results demonstrated in this paper were found to be much better.

The structural error distributions of the three methods are given as shown in Figs. (2-5) and, accordingly, it can be said that there is no clear superiority of one method over the others. However, in the sub-domain and the precision point methods, the structural error distribution is greatly influenced by the arbitrarily selected sub-domains and precision points, whereas in the galerkin method, the error distribution is not affected by the weighting functions selected arbitrarily. In this case, the galerkin method has superiority over the other two methods. Finally, the design algorithm discussed in this study can be applied to different types of mechanisms and also for path and motion synthesis, as well.

FUNDING: This research received no financial support for the research, authorship, and/or publication of this article.

CONFLICTS OF INTEREST: The authors declare that they have no conflict of interest.

\section{REFERENCES}

Akçalı I D (1984). Mekanizma tekniğinde yörünge ve fonksiyon sentezine çeşitli yaklaşımların gözden geçirilmesi. Doğa, 8(1), 1-12.

Akçalı I D \& Dittrich G (1989). Function generation by Galerkin's method. Mechanism and Machine Theory, 24(1), 39-43. https://doi.org/10.1016/0094114X(89)90081-5

Akçalı I D \& Mutlu H (2006). A novel approach in the direct kinematics of Stewart platform mechanisms with planar platforms. Journal of Mechanical Design, 128(1),

252-263. https://doi.org/10.1115/1.1864114

Almadi A N, Dhingra A K \& Kohli D (1996). Closed-form displacement analysis of SDOF 8-link mechanisms. Proceedings of ASME Design Engineering Technology Conference, Irvine, California.

Almadi A N, Dhingra A K \& Kohli D (1995). Displacement analysis of ten-link kinematic chains using homotopy. Proceedings of 9th World Congress on the Theory of Machines and Mechanisms, Milan, Italy, 90-94.

Dhingra A K, Almadi A N \& Kohli D (2000a). Closed-form approach to coupler-curves of multi-loop mechanisms. ASME Journal of Mechanical Design, 122(4), 464-471. https://doi.org/10.1115/1.1290394

Dhingra A K, Almadi A N \& Kohli D (2000b). Closed-form displacement analysis of 8,9 and 10-link mechanisms: Part-II: 9-link 2-DOF and 10-link 3-DOF mechanisms. Mechanisms and Machine Theory, 35(6), 851-869. https://doi.org/10.1016/S0094114X(99)00033-6

Dhingra A K, Almadi A N \& Kohli D (2001a). Closed-form displacement analysis of 10-link mechanisms: Part-I. Mechanisms and Machine Theory, 36(1), 29-56. https://doi.org/10.1016/S0094-114X(00)00040-9

Dhingra A K, Almadi A N and Kohli D (2001b). Closedform displacement analysis of 10-link mechanisms: Part-II: polynomial solutions. Mechanisms and Machine Theory, 36(1), 57-75. https://doi.org/10.1016/S0094-114X(00)00039-2 
Hartenberg R S \& Denavit J (1964). Kinematics synthesis of linkages, McGraw-Hill, New York, USA.

Jaiswal A \& Jawale H P (2018). Synthesis and optimization of four bar mechanism with six design parameters. AIP Conference Proceedings, 1943(1). https://doi.org/10.1063/1.5029590

McCarthy J M \& Joskowicz L (2009). Kinematic synthesis, Cambridge University Press.

Mehar K, Singh S \& Mehar R (2015). Optimal synthesis of four-bar mechanism for function generation with five accuracy points. Inverse Problems in Science and Engineering, 23(7), 1222-1236. https://doi.org/10.1080/17415977.2014.993982

Nolle H (1997). Linkage coupler curve synthesis: a historical review-III spatial synthesis and optimization. Mechanism and Machine Theory, 10(1), 41-55.

Özkul İ \& Mutlu H (2018). Modular approach to the design of path generating planar mechanisms. Turkish Journal of Engineering, 2(2), 60-72. DOI: $10.31127 /$ tuje.345153

Shigley J E (1961). Theory of Machines, McGraw-Hill, New York, USA.
Singh V P, Sharma S \& Thakur B S (2005). Kinematic synthesis and optimization of four-bar linkage. Journal of the Institution of Engineers (India), Part MC, Mechanical Engineering Division, 85, 199-205.

Söylemez E (1985). Mechanisms. Ankara Üniversitesi Basım evi, Ankara, Turkey (in Turkish).

Tinubu S O \& Gupta K C (1984). Optimal synthesis of function generators without the branch defect. ASME, 106(3), 348-354. https://doi.org/10.1115/1.3267418

Wampler C W, Morgan A P \& Sommese A J (1990). Numerical continuation methods for solving polynomial systems arising in kinematics. ASME Journal of Mechanical Design, 112(1), 59-68. https://doi.org/10.1115/1.2912579

Wampler C W, Morgan A P \& Sommese A J (1992). Complete solutions of the nine-point path synthesis problem for four-bar linkages. ASME Journal of Mechanical Design, 114(1), 153-159. https://doi.org/10.1115/1.2916909 
APPENDIX A. Computed coefficients of the abovementioned equations

$a_{p i}=2 a_{k} b_{3} c_{2} f_{1}-2 a_{3} b_{k} c_{2} f_{1}-2 a_{k} b_{2} c_{3} f_{1}+2 a_{2} b_{k} c_{3} f_{1}+2 a_{3} b_{2} c_{k} f_{1}-$ $2 a_{2} b_{3} c_{k} f_{1}-2 a_{k} b_{3} c_{1} f_{2}+2 a_{3} b_{k} c_{1} f_{2}+2 a_{k} b_{1} c_{3} f_{2}-2 a_{1} b_{k} c_{3} f_{2}-$ $2 a_{3} b_{1} c_{k} f_{2}+2 a_{1} b_{3} c_{k} f_{2}+2 a_{k} b_{2} c_{1} f_{3}-2 a_{2} b_{k} c_{1} f_{3}-2 a_{k} b_{1} c_{2} f_{3}+$ $2 a_{1} b_{k} c_{2} f_{3}+2 a_{2} b_{1} c_{k} f_{3}-2 a_{1} b_{2} c_{k} f_{3}-2 a_{3} b_{2} c_{1} f_{k}+2 a_{2} b_{3} c_{1} f_{k}+$ $2 a_{3} b_{1} c_{2} f_{k}-2 a_{1} b_{3} c_{2} f_{k}-2 a_{2} b_{1} c_{3} f_{k}+2 a_{1} b_{2} c_{3} f_{k}$ $\mathrm{i}=1,2 \mathrm{k}=\mathrm{i}+1$

$b_{p i}=a_{k} b_{3} d_{2} f_{1}-a_{3} b_{k} d_{2} f_{1}-a_{k} b_{2} d_{3} f_{1}+a_{2} b_{k} d_{3} f_{1}+a_{3} b_{2} d_{k} f_{1}-$ $a_{2} b_{3} d_{k} f_{1}-a_{k} c_{3} e_{2} f_{1}+a_{3} c_{k} e_{2} f_{1}+a_{k} c_{2} e_{3} f_{1}-a_{2} c_{k} e_{3} f_{1}-a_{3} c_{2} e_{k} f_{1}+$ $a_{2} c_{3} e_{k} f_{1}-a_{k} b_{3} d_{1} f_{2}+a_{3} b_{k} d_{1} f_{2}+a_{k} b_{1} d_{3} f_{2}-a_{1} b_{k} d_{3} f_{2}-a_{3} b_{1} d_{k} f_{2}+$ $a_{1} b_{3} d_{k} f_{2}+a_{k} c_{3} e_{1} f_{2}-a_{3} c_{k} e_{1} f_{2}-a_{k} c_{1} e_{3} f_{2}+a_{1} c_{k} e_{3} f_{2}+a_{3} c_{1} e_{k} f_{2}-$ $a_{1} c_{3} e_{k} f_{2}+a_{k} b_{2} d_{1} f_{3}-a_{2} b_{k} d_{1} f_{3}-a_{k} b_{1} d_{2} f_{3}+a_{1} b_{k} d_{2} f_{3}+a_{2} b_{1} d_{k} f_{3}-$ $a_{1} b_{2} d_{k} f_{3}-a_{k} c_{2} e_{1} f_{3}+a_{2} c_{k} e_{1} f_{3}+a_{k} c_{1} e_{2} f_{3}-a_{1} c_{k} e_{2} f_{3}-a_{2} c_{1} e_{k} f_{3}+$ $a_{1} c_{2} e_{k} f_{3}-a_{3} b_{2} d_{1} f_{k}+a_{2} b_{3} d_{1} f_{k}+a_{3} b_{1} d_{2} f_{k}-a_{1} b_{3} d_{2} f_{k}-a_{2} b_{1} d_{3} f_{k}+$ $a_{1} b_{2} d_{3} f_{k}+a_{3} c_{2} e_{1} f_{k}-a_{2} c_{3} e_{1} f_{k}-a_{3} c_{1} e_{2} f_{k}+a_{1} c_{3} e_{2} f_{k}+a_{2} c_{1} e_{3} f_{k^{-}}$ $\mathrm{a}_{1} \mathrm{c}_{2} \mathrm{e}_{3} \mathrm{f}_{\mathrm{k}^{-}} \quad 2 \mathrm{~b}_{\mathrm{k}} \mathrm{c}_{3} \mathrm{f}_{2} \mathrm{~g}_{1}+2 \mathrm{~b}_{3} \mathrm{Ck}_{2} \mathrm{f}_{1}+2 \mathrm{~b}_{\mathrm{k}} \mathrm{C}_{2} \mathrm{f}_{3} \mathrm{~g}_{1-}-2 \mathrm{~b}_{2} \mathrm{Ck}_{3} \mathrm{f}_{3} \mathrm{~g}_{1-}$ $2 b_{3} c_{2} f_{k} g_{1}+2 b_{2} c_{3} f_{k} g_{1}+2 b_{k} c_{3} f_{1} g_{2}-2 b_{3} c_{k} f_{1} g_{2}-2 b_{k} c_{1} f_{3} g_{2}+$ $2 b_{1} c_{k} f_{3} g_{2}+2 b_{3} c_{1} f_{k} g_{2}-2 b_{1} c_{3} f_{k} g_{2}-2 b_{k} c_{2} f_{1} g_{3}+2 b_{2} c_{k} f_{1} g_{3}+$ $2 b_{k} c_{1} f_{2} g_{3}-2 b_{1} c_{k} f_{2} g_{3}-2 b_{2} c_{1} f_{k} g_{3}+2 b_{1} c_{2} f_{k} g_{3}+2 b_{3} c_{2} f_{1} g_{k}-$ $2 b_{2} c_{3} f_{1} g_{k}-2 b_{3} c_{1} f_{2} g_{k}+2 b_{1} c_{3} f_{2} g_{k}+2 b_{2} c_{1} f_{3} g_{k}-2 b_{1} c_{2} f_{3} g_{k}$ $\mathrm{i}=1,2 \mathrm{k}=\mathrm{i}+1$

$c_{p i}=a_{k} b_{3} d_{2} f_{1}-\quad a_{3} b_{k} d_{2} f_{1}-\quad a_{k} b_{2} d_{3} f_{1}+a_{2} b_{k} d_{3} f_{1}+a_{3} b_{2} d_{k} f_{1}-$ $a_{2} b_{3} d_{k} f_{1}+a_{k} c_{3} e_{2} f_{1}-a_{3} c_{k} e_{2} f_{1}-a_{k} c_{2} e_{3} f_{1}+a_{2} c_{k} e_{3} f_{1}+a_{3} c_{2} e_{k} f_{1}-$ $a_{2} c_{3} e_{k} f_{1}-a_{k} b_{3} d_{1} f_{2}+a_{3} b_{k} d_{1} f_{2}+a_{k} b_{1} d_{3} f_{2}-a_{1} b_{k} d_{3} f_{2}-a_{3} b_{1} d_{k} f_{2}+$ $a_{1} b_{3} d_{k} f_{2}-a_{k} c_{3} e_{1} f_{2}+a_{3} c_{k} e_{1} f_{2}+a_{k} c_{1} e_{3} f_{2}-a_{1} c_{k} e_{3} f_{2}-a_{3} c_{1} e_{k} f_{2}+$ $a_{1} c_{3} e_{k} f_{2}+a_{k} b_{2} d_{1} f_{3}-a_{2} b_{k} d_{1} f_{3}-a_{k} b_{1} d_{2} f_{3}+a_{1} b_{k} d_{2} f_{3}+a_{2} b_{1} d_{k} f_{3}-$ $a_{1} b_{2} d_{k} f_{3}+a_{k} c_{2} e_{1} f_{3}-a_{2} c_{k} e_{1} f_{3}-a_{k} c_{1} e_{2} f_{3}+a_{1} c_{k} e_{2} f_{3}+a_{2} c_{1} e_{k} f_{3}-$ $a_{1} c_{2} e_{k} f_{3}-a_{3} b_{2} d_{1} f_{k}+a_{2} b_{3} d_{1} f_{k}+a_{3} b_{1} d_{2} f_{k}-a_{1} b_{3} d_{2} f_{k}-a_{2} b_{1} d_{3} f_{k}+$ $a_{1} b_{2} d_{3} f_{k}-a_{3} c_{2} e_{1} f_{k}+a_{2} c_{3} e_{1} f_{k}+a_{3} c_{1} e_{2} f_{k}-a_{1} c_{3} e_{2} f_{k}-a_{2} c_{1} e_{3} f_{k}+$ $\mathrm{a}_{1} \mathrm{c}_{2} \mathrm{e}_{3} \mathrm{f}_{\mathrm{k}}$

$\mathrm{i}=1,2 \mathrm{k}=\mathrm{i}+1$

$d_{p i}=a_{k} c_{3} d_{2} f_{1-} \quad a_{3} c_{k} d_{2} f_{1-} \quad a_{k} c_{2} d_{3} f_{1}+a_{2} c_{k} d_{3} f_{1}+a_{3} c_{2} d k f_{1}-$ $a_{2} c_{3} d_{k} f_{1}-a_{k} b_{3} e_{2} f_{1}+a_{3} b_{k} e_{2} f_{1}+a_{k} b_{2} e_{3} f_{1}-a_{2} b_{k} e_{3} f_{1}-a_{3} b_{2} e_{k} f_{1}+$ $a_{2} b_{3} e_{k} f_{1}-a_{k} c_{3} d_{1} f_{2}+a_{3} c_{k} d_{1} f_{2}+a_{k} c_{1} d_{3} f_{2}-a_{1} c_{k} d_{3} f_{2}-a_{3} c_{1} d_{k} f_{2}+$ $a_{1} c_{3} d_{k} f_{2}+a_{k} b_{3} e_{1} f_{2}-a_{3} b_{k} e_{1} f_{2}-a_{k} b_{1} e_{3} f_{2}+a_{1} b_{k} e_{3} f_{2}+a_{3} b_{1} e_{k} f_{2}-$ $a_{1} b_{3} e_{k} f_{2}+a_{k} c_{2} d_{1} f_{3}-a_{2} c_{k} d_{1} f_{3}-a_{k} c_{1} d_{2} f_{3}+a_{1} c_{k} d_{2} f_{3}+a_{2} c_{1} d_{k} f_{3}-$ $a_{1} c_{2} d_{k} f_{3}-a_{k} b_{2} e_{1} f_{3}+a_{2} b_{k} e_{1} f_{3}+a_{k} b_{1} e_{2} f_{3}-a_{1} b_{k} e_{2} f_{3}-a_{2} b_{1} e_{k} f_{3}+$ $a_{1} b_{2} e_{k} f_{3}-a_{3} c_{2} d_{1} f_{k}+a_{2} c_{3} d_{1} f_{k}+a_{3} c_{1} d_{2} f_{k}-a_{1} c_{3} d_{2} f_{k}-a_{2} c_{1} d_{3} f_{k}+$ $a_{1} c_{2} d_{3} f_{k}+a_{3} b_{2} e_{1} f_{k}-a_{2} b_{3} e_{1} f_{k^{-}} a_{3} b_{1} e_{2} f_{k}+a_{1} b_{3} e_{2} f_{k}+a_{2} b_{1} e_{3} f_{k}-$ $a_{1} b_{2} e_{3} f_{k}$

$\mathrm{i}=1,2 \mathrm{k}=\mathrm{i}+1$

$e_{p i}=-b_{k} d_{3} f_{2} g_{1}+b_{3} d_{k} f_{2} g_{1}+c_{k} e_{3} f_{2} g_{1-} \quad c_{3} e_{k} f_{2} g_{1}+b_{k} d_{2} f_{3} g_{1-}$ $b_{2} d_{k} f_{3} g_{1}-c_{k} e_{2} f_{3} g_{1}+c_{2} e_{k} f_{3} g_{1}-b_{3} d_{2} f_{k} g_{1}+b_{2} d_{3} f_{k} g_{1}+c_{3} e_{2} f_{k} g_{1}-$ $c_{2} e_{3} f_{k} g_{1}+b_{k} d_{3} f_{1} g_{2}-b_{3} d_{k} f_{1} g_{2}-c_{k} e_{3} f_{1} g_{2}+c_{3} e_{k} f_{1} g_{2}-b_{k} d_{1} f_{3} g_{2}+$ $b_{1} d_{k} f_{3} g_{2}+c_{k} e_{1} f_{3} g_{2}-c_{1} e_{k} f_{3} g_{2}+b_{3} d_{1} f_{k} g_{2}-b_{1} d_{3} f_{k} g_{2}-c_{3} e_{1} f_{k} g_{2}+$ $c_{1} e_{3} f_{k} g_{2}-b_{k} d_{2} f_{1} g_{3}+b_{2} d_{k} f_{1} g_{3}+c_{k} e_{2} f_{1} g_{3}-c_{2} e_{k} f_{1} g_{3}+b_{k} d_{1} f_{2} g_{3}-$ $b_{1} d_{k} f_{2} g_{3}-c_{k} e_{1} f_{2} g_{3}+c_{1} e_{k} f_{2} g_{3}-b_{2} d_{1} f_{k} g_{3}+b_{1} d_{2} f_{k} g_{3}+c_{2} e_{1} f_{k} g_{3}-$ $c_{1} e_{2} f_{k} g_{3}+b_{3} d_{2} f_{1} g_{k}-b_{2} d_{3} f_{1} g_{k}-c_{3} e_{2} f_{1} g_{k}+c_{2} e_{3} f_{1} g_{k}-b_{3} d_{1} f_{2} g_{k}+$ $b_{1} d_{3} f_{2} g_{k}+c_{3} e_{1} f_{2} g_{k}-c_{1} e_{3} f_{2} g_{k}+b_{2} d_{1} f_{3} g_{k}-b_{1} d_{2} f_{3} g_{k^{-}} c_{2} e_{1} f_{3} g_{k}+$ $\mathrm{c}_{1} \mathrm{e}_{2} \mathrm{f}_{3} \mathrm{~g}_{\mathrm{k}}$

$\mathrm{i}=1,2 \mathrm{k}=\mathrm{i}+1$

$f_{p i}=-b_{k} d_{3} f_{2} g_{1}+\quad b_{3} d_{k} f_{2} g_{1}-\quad c_{k} e_{3} f_{2} g_{1}+\quad c_{3} e_{k} f_{2} g_{1}+\quad b_{k} d_{2} f_{3} g_{1}-$ $b_{2} d_{k} f_{3} g_{1}+c_{k} e_{2} f_{3} g_{1}-c_{2} e_{k} f_{3} g_{1}-b_{3} d_{2} f_{k} g_{1}+b_{2} d_{3} f_{k} g_{1}-c_{3} e_{2} f_{k} g_{1}+$ $c_{2} e_{3} f_{k} g_{1}+b_{k} d_{3} f_{1} g_{2}-b_{3} d_{k} f_{1} g_{2}+c_{k} e_{3} f_{1} g_{2}-c_{3} e_{k} f_{1} g_{2}-b_{k} d_{1} f_{3} g_{2}+$ $b_{1} d_{k} f_{3} g_{2}-c_{k} e_{1} f_{3} g_{2}+c_{1} e_{k} f_{3} g_{2}+b_{3} d_{1} f_{k} g_{2}-b_{1} d_{3} f_{k} g_{2}+c_{3} e_{1} f_{k} g_{2}-$ $c_{1} e_{3} f_{k} g_{2}-b_{k} d_{2} f_{1} g_{3}+b_{2} d_{k} f_{1} g_{3}-c_{k} e_{2} f_{1} g_{3}+c_{2} e_{k} f_{1} g_{3}+b_{k} d_{1} f_{2} g_{3}-$ $b_{1} d_{k} f_{2} g_{3}+c_{k} e_{1} f_{2} g_{3}-c_{1} e_{k} f_{2} g_{3}-b_{2} d_{1} f_{k} g_{3}+b_{1} d_{2} f_{k} g_{3}-c_{2} e_{1} f_{k} g_{3}+$ $c_{1} e_{2} f_{k} g_{3}+b_{3} d_{2} f_{1} g_{k}-b_{2} d_{3} f_{1} g_{k}+c_{3} e_{2} f_{1} g_{k}-c_{2} e_{3} f_{1} g_{k}-b_{3} d_{1} f_{2} g_{k}+$ $b_{1} d_{3} f_{2} g_{k}-c_{3} e_{1} f_{2} g_{k}+c_{1} e_{3} f_{2} g_{k}+b_{2} d_{1} f_{3} g_{k}-b_{1} d_{2} f_{3} g_{k}+c_{2} e_{1} f_{3} g_{k}$ $\mathrm{c}_{1} \mathrm{e}_{2} \mathrm{f}_{3} \mathrm{gk}_{\mathrm{k}}$

$\mathrm{i}=1,2 \mathrm{k}=\mathrm{i}+1$

$g_{p i}=-c_{k} d_{3} f_{2} g_{1}+\quad c_{3} d_{k} f_{2} g_{1}+\quad b_{k} e_{3} f_{2} g_{1}-\quad b_{3} e_{k} f_{2} g_{1}+\quad c_{k} d_{2} f_{3} g_{1}-$ $c_{2} d_{k} f_{3} g_{1}-b_{k} e_{2} f_{3} g_{1}+b_{2} e_{k} f_{3} g_{1}-c_{3} d_{2} f_{k} g_{1}+c_{2} d_{3} f_{k} g_{1}+b_{3} e_{2} f_{k} g_{1}-$ $b_{2} e_{3} f_{k} g_{1}+c_{k} d_{3} f_{1} g_{2}-c_{3} d_{k} f_{1} g_{2}-b_{k} e_{3} f_{1} g_{2}+b_{3} e_{k} f_{1} g_{2}-c_{k} d_{1} f_{3} g_{2}+$ $c_{1} d_{k} f_{3} g_{2}+b_{k} e_{1} f_{3} g_{2}-b_{1} e_{k} f_{3} g_{2}+c_{3} d_{1} f_{k} g_{2}-c_{1} d_{3} f_{k} g_{2}-b_{3} e_{1} f_{k} g_{2}+$ $b_{1} e_{3} f_{k} g_{2}-c_{k} d_{2} f_{1} g_{3}+c_{2} d_{k} f_{1} g_{3}+b_{k} e_{2} f_{1} g_{3}-b_{2} e_{k} f_{1} g_{3}+c_{k} d_{1} f_{2} g_{3}-$ $c_{1} d_{k} f_{2} g_{3}-b_{k} e_{1} f_{2} g_{3}+b_{1} e_{k} f_{2} g_{3}-c_{2} d_{1} f_{k} g_{3}+c_{1} d_{2} f_{k} g_{3}+b_{2} e_{1} f_{k} g_{3}-$ $b_{1} e_{2} f_{k} g_{3}+c_{3} d_{2} f_{1} g_{k}-c_{2} d_{3} f_{1} g_{k^{-}} b_{3} e_{2} f_{1} g_{k}+b_{2} e_{3} f_{1} g_{k^{-}} c_{3} d_{1} f_{2} g_{k}+$ $c_{1} d_{3} f_{2} g_{k}+b_{3} e_{1} f_{2} g_{k}-b_{1} e_{3} f_{2} g_{k}+c_{2} d_{1} f_{3} g_{k}-c_{1} d_{2} f_{3} g_{k}-b_{2} e_{1} f_{3} g_{k}+$ $\mathrm{b}_{1} \mathrm{e}_{2} \mathrm{f}_{3} \mathrm{gk}_{\mathrm{k}}$

$\mathrm{i}=1,2 \mathrm{k}=\mathrm{i}+1$

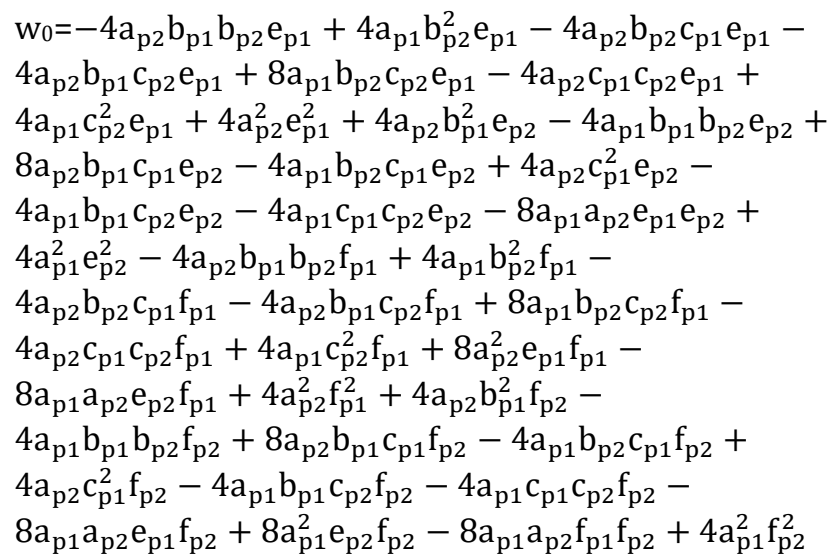
(19)

$\mathrm{w}_{1}=-16 \mathrm{a}_{\mathrm{p} 2} \mathrm{~b}_{\mathrm{p} 2} \mathrm{~d}_{\mathrm{p} 1} \mathrm{e}_{\mathrm{p} 1}-16 \mathrm{a}_{\mathrm{p} 2} \mathrm{c}_{\mathrm{p} 2} \mathrm{~d}_{\mathrm{p} 1} \mathrm{e}_{\mathrm{p} 1}-$

$16 a_{p 2} b_{p 1} d_{p 2} e_{p 1}+32 a_{p 1} b_{p 2} d_{p 2} e_{p 1}-16 a_{p 2} c_{p 1} d_{p 2} e_{p 1}+$

$32 \mathrm{a}_{\mathrm{p} 1} \mathrm{c}_{\mathrm{p} 2} \mathrm{~d}_{\mathrm{p} 2} \mathrm{e}_{\mathrm{p} 1}+32 \mathrm{a}_{\mathrm{p} 2} \mathrm{~b}_{\mathrm{p} 1} \mathrm{~d}_{\mathrm{p} 1} \mathrm{e}_{\mathrm{p} 2}-16 \mathrm{a}_{\mathrm{p} 1} \mathrm{~b}_{\mathrm{p} 2} \mathrm{~d}_{\mathrm{p} 1} \mathrm{e}_{\mathrm{p} 2}+$

$32 a_{p 2} c_{p 1} d_{p 1} e_{p 2}-16 a_{p 1} c_{p 2} d_{p 1} e_{p 2}-16 a_{p 1} b_{p 1} d_{p 2} e_{p 2}-$

$16 a_{p 1} c_{p 1} d_{p 2} e_{p 2}-16 a_{p 2} b_{p 2} d_{p 1} f_{p 1}-16 a_{p 2} c_{p 2} d_{p 1} f_{p 1}-$

$16 a_{p 2} b_{p 1} d_{p 2} f_{p 1}+32 a_{p 1} b_{p 2} d_{p 2} f_{p 1}-16 a_{p 2} c_{p 1} d_{p 2} f_{p 1}+$

$32 a_{p 1} c_{p 2} d_{p 2} f_{p 1}+32 a_{p 2} b_{p 1} d_{p 1} f_{p 2}-16 a_{p 1} b_{p 2} d_{p 1} f_{p 2}+$

$32 a_{p 2} c_{p 1} d_{p 1} f_{p 2}-16 a_{p 1} c_{p 2} d_{p 1} f_{p 2}-16 a_{p 1} b_{p 1} d_{p 2} f_{p 2}-$

$16 a_{p 1} c_{p 1} d_{p 2} f_{p 2}-16 a_{p 2} b_{p 1} b_{p 2} g_{p 1}+16 a_{p 1} b_{p 2}^{2} g_{p 1}-$

$16 a_{p 2} b_{p 2} c_{p 1} g_{p 1}-16 a_{p 2} b_{p 1} c_{p 2} g_{p 1}+32 a_{p 1} b_{p 2} c_{p 2} g_{p 1}-$

$16 a_{p 2} c_{p 1} c_{p 2} g_{p 1}+16 a_{p 1} c_{p 2}^{2} g_{p 1}+32 a_{p 2}^{2} e_{p 1} g_{p 1}-$

$32 a_{p 1} a_{p 2} e_{p 2} g_{p 1}+32 a_{p 2}^{2} f_{p 1} g_{p 1}-32 a_{p 1} a_{p 2} f_{p 2} g_{p 1}+$

$16 a_{p 2} b_{p 1}^{2} g_{p 2}-16 a_{p 1} b_{p 1} b_{p 2} g_{p 2}+32 a_{p 2} b_{p 1} c_{p 1} g_{p 2}-$

$16 a_{p 1} b_{p 2} c_{p 1} g_{p 2}+16 a_{p 2} c_{p 1}^{2} g_{p 2}-16 a_{p 1} b_{p 1} c_{p 2} g_{p 2}-$

$16 a_{p 1} c_{p 1} c_{p 2} g_{p 2}-32 a_{p 1} a_{p 2} e_{p 1} g_{p 2}+32 a_{p 1}^{2} e_{p 2} g_{p 2}-$

$32 a_{p 1} a_{p 2} f_{p 1} g_{p 2}+32 a_{p 1}^{2} f_{p 2} g_{p 2}$

$\mathrm{w}_{2}=-24 \mathrm{a}_{\mathrm{p} 2} \mathrm{~b}_{\mathrm{p} 1} \mathrm{~b}_{\mathrm{p} 2} \mathrm{e}_{\mathrm{p} 1}+72 \mathrm{a}_{\mathrm{p} 1}^{2} \mathrm{~b}_{\mathrm{p} 2}^{2} \mathrm{e}_{\mathrm{p} 1}+8 \mathrm{a}_{\mathrm{p} 2} \mathrm{~b}_{\mathrm{p} 2} \mathrm{c}_{\mathrm{p} 1} \mathrm{e}_{\mathrm{p} 1}+$ $8 a_{p 2} b_{p 1} c_{p 2} e_{p 1}-16 a_{p 1} b_{p 2} c_{p 2} e_{p 1}+40 a_{p 2} c_{p 1} c_{p 2} e_{p 1}-$ $40 a_{p 1} c_{p 2}^{2} e_{p 1}-64 a_{p 2} d_{p 1} d_{p 2} e_{p 1}+64 a_{p 1} d_{p 2}^{2} e_{p 1}+$

$24 \mathrm{a}_{\mathrm{p} 2}^{2} \mathrm{e}_{\mathrm{p} 1}^{2}+24 \mathrm{a}_{\mathrm{p} 2} \mathrm{~b}_{\mathrm{p} 1}^{2} \mathrm{e}_{\mathrm{p} 2}-24 \mathrm{a}_{\mathrm{p} 1} \mathrm{~b}_{\mathrm{p} 1} \mathrm{~b}_{\mathrm{p} 2} \mathrm{e}_{\mathrm{p} 2}-$ $16 a_{p 2} b_{p 1} c_{p 1} e_{p 2}+8 a_{p 1} b_{p 2} c_{p 1} e_{p 2}-40 a_{p 2} c_{p 1}^{2} e_{p 2}+$ $8 a_{p 1} b_{p 1} c_{p 2} e_{p 2}+40 a_{p 1} c_{p 1} c_{p 2} e_{p 2}+64 a_{p 2} d_{p 1}^{2} e_{p 2}-$ $64 a_{p 1} d_{p 1} d_{p 2} e_{p 2}-48 a_{p 1} a_{p 2} e_{p 1} e_{p 2}+8 a_{p 2} b_{p 1} b_{p 2} f_{p 1}-$ $24 a_{p 1}^{2} b_{p 2}^{2} f_{p 1}+40 a_{p 2} b_{p 2} c_{p 1} f_{p 1}+40 a_{p 2} b_{p 1} c_{p 2} f_{p 1}-$ 
$80 a_{p 1} b_{p 2} c_{p 2} f_{p 1}+72 a_{p 2} c_{p 1} c_{p 2} f_{p 1}-72 a_{p 1} c_{p 2}^{2} f_{p 1}-$ $64 a_{p 2} d_{p 1} d_{p 2} f_{p 1}+64 a_{p 1} d_{p 2}^{2} f_{p 1}-16 a_{p 2}^{2} e_{p 1} f_{p 1}+$ $16 a_{p 1} a_{p 2} e_{p 2} f_{p 1}-40 a_{p 2}^{2} f_{p 1}^{2}-8 a_{p 2} b_{p 1}^{2} f_{p 2}+$ $8 a_{p 1} b_{p 1} b_{p 2} f_{p 2}-80 a_{p 2} b_{p 1} c_{p 1} f_{p 2}+40 a_{p 1} b_{p 2} c_{p 1} f_{p 2}-$ $72 a_{p 2} c_{p 1}^{2} f_{p 2}+40 a_{p 1} b_{p 1} c_{p 2} f_{p 2}+72 a_{p 1} c_{p 1} c_{p 2} f_{p 2}+$ $64 a_{p 2} d_{p 1}^{2} f_{p 2}-64 a_{p 1} d_{p 1} d_{p 2} f_{p 2}+16 a_{p 1} a_{p 2} e_{p 1} f_{p 2}-$ $16 a_{p 1}^{2} e_{p 2} f_{p 2}+80 a_{p 1} a_{p 2} f_{p 1} f_{p 2}-40 a_{p 1}^{2} f_{p 2}^{2}-$

$64 a_{p 2} b_{p 2} d_{p 1} g_{p 1}-64 a_{p 2} c_{p 2} d_{p 1} g_{p 1}-64 a_{p 2} b_{p 1} d_{p 2} g_{p 1}+$ $128 a_{p 1} b_{p 2} d_{p 2} g_{p 1}-64 a_{p 2} c_{p 1} d_{p 2} g_{p 1}+$ $128 a_{p 1} c_{p 2} d_{p 2} g_{p 1}+64 a_{p 2}^{2} g_{p 1}^{2}+128 a_{p 2} b_{p 1} d_{p 1} g_{p 2}-$ $64 a_{p 1} b_{p 2} d_{p 1} g_{p 2}+128 a_{p 2} c_{p 1} d_{p 1} g_{p 2}-64 a_{p 1} c_{p 2} d_{p 1} g_{p 2}-$ $64 \mathrm{a}_{\mathrm{p} 1} \mathrm{~b}_{\mathrm{p} 1} \mathrm{~d}_{\mathrm{p} 2} \mathrm{~g}_{\mathrm{p} 2}-64 \mathrm{a}_{\mathrm{p} 1} \mathrm{c}_{\mathrm{p} 1} \mathrm{~d}_{\mathrm{p} 2} \mathrm{~g}_{\mathrm{p} 2}-$ $128 a_{p 1} a_{p 2} g_{p 1} g_{p 2}+64 a_{p 1}^{2} g_{p 2}^{2}$

$w_{3}=-48 a_{p 2} b_{p 2} d_{p 1} e_{p 1}+80 a_{p 2} c_{p 2} d_{p 1} e_{p 1}-$

$48 a_{p 2} b_{p 1} d_{p 2} e_{p 1}+96 a_{p 1} b_{p 2} d_{p 2} e_{p 1}+80 a_{p 2} c_{p 1} d_{p 2} e_{p 1}-$ $160 a_{p 1} c_{p 2} d_{p 2} e_{p 1}+96 a_{p 2} b_{p 1} d_{p 1} e_{p 2}-48 a_{p 1} b_{p 2} d_{p 1} e_{p 2}-$ $160 a_{p 2} c_{p 1} d_{p 1} e_{p 2}+80 a_{p 1} c_{p 2} d_{p 1} e_{p 2}-48 a_{p 1} b_{p 1} d_{p 2} e_{p 2}+$ $80 a_{p 1} c_{p 1} d_{p 2} e_{p 2}+80 a_{p 2} b_{p 2} d_{p 1} f_{p 1}+208 a_{p 2} c_{p 2} d_{p 1} f_{p 1}+$ $80 a_{p 2} b_{p 1} d_{p 2} f_{p 1}-160 a_{p 1} b_{p 2} d_{p 2} f_{p 1}+208 a_{p 2} c_{p 1} d_{p 2} f_{p 1}-$ $416 a_{p 1} c_{p 2} d_{p 2} f_{p 1}-160 a_{p 2} b_{p 1} d_{p 1} f_{p 2}+80 a_{p 1} b_{p 2} d_{p 1} f_{p 2}-$ $416 a_{p 2} c_{p 1} d_{p 1} f_{p 2}+208 a_{p 1} c_{p 2} d_{p 1} f_{p 2}+80 a_{p 1} b_{p 1} d_{p 2} f_{p 2}+$ $208 a_{p 1} c_{p 1} d_{p 2} f_{p 2}-48 a_{p 2} b_{p 1} b_{p 2} g_{p 1}+48 a_{p 1} b_{p 2}^{2} g_{p 1}+$ $80 a_{p 2} b_{p 2} c_{p 1} g_{p 1}+80 a_{p 2} b_{p 1} c_{p 2} g_{p 1}-160 a_{p 1} b_{p 2} c_{p 2} g_{p 1}+$ $208 a_{p 2} c_{p 1} c_{p 2} g_{p 1}-208 a_{p 1} c_{p 2}^{2} g_{p 1}-256 a_{p 2} d_{p 1} d_{p 2} g_{p 1}+$ $256 a_{p 1} d_{p 2}^{2} g_{p 1}+96 a_{p 2}^{2} e_{p 1} g_{p 1}-96 a_{p 1} a_{p 2} e_{p 2} g_{p 1}-$ $160 a_{p 2}^{2} f_{p 1} g_{p 1}+160 a_{p 1} a_{p 2} f_{p 2} g_{p 1}+48 a_{p 2} b_{p 1}^{2} g_{p 2}-$ $48 a_{p 1} b_{p 1} b_{p 2} g_{p 2}-160 a_{p 2} b_{p 1} c_{p 1} g_{p 2}+80 a_{p 1} b_{p 2} c_{p 1} g_{p 2}-$ $208 \mathrm{a}_{\mathrm{p} 2} \mathrm{c}_{\mathrm{p} 1}^{2} \mathrm{~g}_{\mathrm{p} 2}+80 \mathrm{a}_{\mathrm{p} 1} \mathrm{~b}_{\mathrm{p} 1} \mathrm{c}_{\mathrm{p} 2} \mathrm{~g}_{\mathrm{p} 2}+208 \mathrm{a}_{\mathrm{p} 1} \mathrm{c}_{\mathrm{p} 1} \mathrm{c}_{\mathrm{p} 2} \mathrm{~g}_{\mathrm{p} 2}+$ $256 a_{p 2} d_{p 1}^{2} g_{p 2}-256 a_{p 1} d_{p 1} d_{p 2} g_{p 2}-96 a_{p 1} a_{p 2} e_{p 1} g_{p 2}+$ $96 a_{p 1}^{2} e_{p 2} g_{p 2}+160 a_{p 1} a_{p 2} f_{p 1} g_{p 2}-160 a_{p 1}^{2} f_{p 2} g_{p 2}$

$\mathrm{w}_{4}=-60 \mathrm{a}_{\mathrm{p} 2} \mathrm{~b}_{\mathrm{p} 1} \mathrm{~b}_{\mathrm{p} 2} \mathrm{e}_{\mathrm{p} 1}+60 \mathrm{a}_{\mathrm{p} 1} \mathrm{~b}_{\mathrm{p} 2}^{2} \mathrm{e}_{\mathrm{p} 1}+$ $68 a_{p 2} b_{p 2} c_{p 1} e_{p 1}+68 a_{p 2} b_{p 1} c_{p 2} e_{p 1}-136 a_{p 1} b_{p 2} c_{p 2} e_{p 1}-$ $60 \mathrm{a}_{\mathrm{p} 2} \mathrm{c}_{\mathrm{p} 1} \mathrm{c}_{\mathrm{p} 2} \mathrm{e}_{\mathrm{p} 1}+60 \mathrm{a}_{\mathrm{p} 1} \mathrm{c}_{\mathrm{p} 2}^{2} \mathrm{e}_{\mathrm{p} 1}+60 \mathrm{a}_{\mathrm{p} 2}^{2} \mathrm{e}_{\mathrm{p} 1}^{2}+$ $60 a_{p 2} b_{p 1}^{2} e_{p 2}-60 a_{p 1} b_{p 1} b_{p 2} e_{p 2}-136 a_{p 2} b_{p 1} c_{p 1} e_{p 2}+$ $68 \mathrm{a}_{\mathrm{p} 1} \mathrm{~b}_{\mathrm{p} 2} \mathrm{c}_{\mathrm{p} 1} \mathrm{e}_{\mathrm{p} 2}+60 \mathrm{a}_{\mathrm{p} 2} \mathrm{c}_{\mathrm{p} 1}^{2} \mathrm{e}_{\mathrm{p} 2}+68 \mathrm{a}_{\mathrm{p} 1} \mathrm{~b}_{\mathrm{p} 1} \mathrm{c}_{\mathrm{p} 2} \mathrm{e}_{\mathrm{p} 2}-$ $60 \mathrm{a}_{\mathrm{p} 1} \mathrm{c}_{\mathrm{p} 1} \mathrm{c}_{\mathrm{p} 2} \mathrm{e}_{\mathrm{p} 2}-120 \mathrm{a}_{\mathrm{p} 1} \mathrm{a}_{\mathrm{p} 2} \mathrm{e}_{\mathrm{p} 1} \mathrm{e}_{\mathrm{p} 2}+60 \mathrm{a}_{\mathrm{p} 1}^{2} \mathrm{e}_{\mathrm{p} 2}^{2}+$ $68 a_{p 2} b_{p 1} b_{p 2} f_{p 1}-68 a_{p 1} b_{p 2}^{2} f_{p 1}-60 a_{p 2} b_{p 2} c_{p 1} f_{p 1}-$ $60 a_{p 2} b_{p 1} c_{p 2} f_{p 1}+120 a_{p 1} b_{p 2} c_{p 2} f_{p 1}-444 a_{p 2} c_{p 1} c_{p 2} f_{p 1}+$ $444 a_{p 1} c_{p 2}^{2} f_{p 1}+512 a_{p 2} d_{p 1} d_{p 2} f_{p 1}-512 a_{p 1} d_{p 2}^{2} f_{p 1}-$ $136 a_{p 2}^{2} e_{p 1} f_{p 1}+136 a_{p 1} a_{p 2} e_{p 2} f_{p 1}+60 a_{p 2}^{2} f_{p 1}^{2}-$ $68 a_{p 2} b_{p 1}^{2} f_{p 2}+68 a_{p 1} b_{p 1} b_{p 2} f_{p 2}+120 a_{p 2} b_{p 1} c_{p 1} f_{p 2}-$ $60 a_{p 1} b_{p 2} c_{p 1} f_{p 2}+444 a_{p 2} c_{p 1}^{2} f_{p 2}-60 a_{p 1} b_{p 1} c_{p 2} f_{p 2}-$ $444 a_{p 1} c_{p 1} c_{p 2} f_{p 2}-512 a_{p 2} d_{p 1}^{2} f_{p 2}+512 a_{p 1} d_{p 1} d_{p 2} f_{p 2}+$ $136 a_{p 1} a_{p 2} e_{p 1} f_{p 2}-136 a_{p 1}^{2} e_{p 2} f_{p 2}-120 a_{p 1} a_{p 2} f_{p 1} f_{p 2}+$ $60 a_{p 1}^{2} f_{p 2}^{2}+512 a_{p 2} c_{p 2} d_{p 1} g_{p 1}+512 a_{p 2} c_{p 1} d_{p 2} g_{p 1}-$ $1024 a_{p 1} c_{p 2} d_{p 2} g_{p 1}-1024 a_{p 2} c_{p 1} d_{p 1} g_{p 2}+$ $512 a_{p 1} c_{p 2} d_{p 1} g_{p 2}+512 a_{p 1} c_{p 1} d_{p 2} g_{p 2}$

$\mathrm{w}_{5}=-32 \mathrm{a}_{\mathrm{p} 2} \mathrm{~b}_{\mathrm{p} 2} \mathrm{~d}_{\mathrm{p} 1} \mathrm{e}_{\mathrm{p} 1}+96 \mathrm{a}_{\mathrm{p} 2} \mathrm{c}_{\mathrm{p} 2} \mathrm{~d}_{\mathrm{p} 1} \mathrm{e}_{\mathrm{p} 1}-$ $32 a_{p 2} b_{p 1} d_{p 2} e_{p 1}+64 a_{p 1} b_{p 2} d_{p 2} e_{p 1}+96 a_{p 2} c_{p 1} d_{p 2} e_{p 1}-$ $192 a_{p 1} c_{p 2} d_{p 2} e_{p 1}+64 a_{p 2} b_{p 1} d_{p 1} e_{p 2}-32 a_{p 1} b_{p 2} d_{p 1} e_{p 2}-$ $192 a_{p 2} c_{p 1} d_{p 1} e_{p 2}+96 a_{p 1} c_{p 2} d_{p 1} e_{p 2}-32 a_{p 1} b_{p 1} d_{p 2} e_{p 2}+$ $96 a_{p 1} c_{p 1} d_{p 2} e_{p 2}+96 a_{p 2} b_{p 2} d_{p 1} f_{p 1}-800 a_{p 2} c_{p 2} d_{p 1} f_{p 1}+$
$96 a_{p 2} b_{p 1} d_{p 2} f_{p 1}-192 a_{p 1} b_{p 2} d_{p 2} f_{p 1}-800 a_{p 2} c_{p 1} d_{p 2} f_{p 1}+$ $1600 a_{p 1} c_{p 2} d_{p 2} f_{p 1}-192 a_{p 2} b_{p 1} d_{p 1} f_{p 2}+$

$96 a_{p 1} b_{p 2} d_{p 1} f_{p 2}+1600 a_{p 2} c_{p 1} d_{p 1} f_{p 2}-$

$800 a_{p 1} c_{p 2} d_{p 1} f_{p 2}+96 a_{p 1} b_{p 1} d_{p 2} f_{p 2}-800 a_{p 1} c_{p 1} d_{p 2} f_{p 2}-$ $32 a_{p 2} b_{p 1} b_{p 2} g_{p 1}+32 a_{p 1} b_{p 2}^{2} g_{p 1}+96 a_{p 2} b_{p 2} c_{p 1} g_{p 1}+$

$96 \mathrm{a}_{\mathrm{p} 2} \mathrm{~b}_{\mathrm{p} 1} \mathrm{c}_{\mathrm{p} 2} \mathrm{~g}_{\mathrm{p} 1}-192 \mathrm{a}_{\mathrm{p} 1} \mathrm{~b}_{\mathrm{p} 2} \mathrm{c}_{\mathrm{p} 2} \mathrm{~g}_{\mathrm{p} 1}-$

$800 a_{p 2} c_{p 1} c_{p 2} g_{p 1}+800 a_{p 1} c_{p 2}^{2} g_{p 1}+768 a_{p 2} d_{p 1} d_{p 2} g_{p 1}-$

$768 a_{p 1} d_{p 2}^{2} g_{p 1}+64 a_{p 2}^{2} e_{p 1} g_{p 1}-64 a_{p 1} a_{p 2} e_{p 2} g_{p 1}-$

$192 a_{p 2}^{2} f_{p 1} g_{p 1}+192 a_{p 1} a_{p 2} f_{p 2} g_{p 1}+32 a_{p 2} b_{p 1}^{2} g_{p 2}-$

$32 a_{p 1} b_{p 1} b_{p 2} g_{p 2}-192 a_{p 2} b_{p 1} c_{p 1} g_{p 2}+96 a_{p 1} b_{p 2} c_{p 1} g_{p 2}+$ $800 a_{p 2} c_{p 1}^{2} g_{p 2}+96 a_{p 1} b_{p 1} c_{p 2} g_{p 2}-800 a_{p 1} c_{p 1} c_{p 2} g_{p 2}-$

$768 a_{p 2} d_{p 1}^{2} g_{p 2}+768 a_{p 1} d_{p 1} d_{p 2} g_{p 2}-64 a_{p 1} a_{p 2} e_{p 1} g_{p 2}+$

$64 a_{p 1}^{2} e_{p 2} g_{p 2}+192 a_{p 1} a_{p 2} f_{p 1} g_{p 2}-192 a_{p 1}^{2} f_{p 2} g_{p 2}$

$\mathrm{w}_{6}=-80 \mathrm{a}_{\mathrm{p} 2} \mathrm{~b}_{\mathrm{p} 1} \mathrm{~b}_{\mathrm{p} 2} \mathrm{e}_{\mathrm{p} 1}+80 \mathrm{a}_{\mathrm{p} 1} \mathrm{~b}_{\mathrm{p} 2}^{2} \mathrm{e}_{\mathrm{p} 1}+$

$112 \mathrm{a}_{\mathrm{p} 2} \mathrm{~b}_{\mathrm{p} 2} \mathrm{c}_{\mathrm{p} 1} \mathrm{e}_{\mathrm{p} 1}+112 \mathrm{a}_{\mathrm{p} 2} \mathrm{~b}_{\mathrm{p} 1} \mathrm{c}_{\mathrm{p} 2} \mathrm{e}_{\mathrm{p} 1}-$

$224 \mathrm{a}_{\mathrm{p} 1} \mathrm{~b}_{\mathrm{p} 2} \mathrm{c}_{\mathrm{p} 2} \mathrm{e}_{\mathrm{p} 1}-208 \mathrm{a}_{\mathrm{p} 2} \mathrm{c}_{\mathrm{p} 1} \mathrm{c}_{\mathrm{p} 2} \mathrm{e}_{\mathrm{p} 1}+208 \mathrm{a}_{\mathrm{p} 1} \mathrm{c}_{\mathrm{p} 2}^{2} \mathrm{e}_{\mathrm{p} 1}+$

$128 a_{p 2} d_{p 1} d_{p 2} e_{p 1}-128 a_{p 1} d_{p 2}^{2} e_{p 1}+80 a_{p 2}^{2} e_{p 1}^{2}+$

$80 a_{p 2} b_{p 1}^{2} e_{p 2}-80 a_{p 1} b_{p 1} b_{p 2} e_{p 2}-224 a_{p 2} b_{p 1} c_{p 1} e_{p 2}+$

$112 a_{p 1} b_{p 2} c_{p 1} e_{p 2}+208 a_{p 2} c_{p 1}^{2} e_{p 2}+112 a_{p 1} b_{p 1} c_{p 2} e_{p 2}-$

$208 a_{p 1} c_{p 1} c_{p 2} e_{p 2}-128 a_{p 2} d_{p 1}^{2} e_{p 2}+128 a_{p 1} d_{p 1} d_{p 2} e_{p 2}-$

$160 a_{p 1} a_{p 2} e_{p 1} e_{p 2}+80 a_{p 1}^{2} e_{p 2}^{2}+112 a_{p 2} b_{p 1} b_{p 2} f_{p 1}-$

$112 a_{p 1} b_{p 2}^{2} f_{p 1}-208 a_{p 2} b_{p 2} c_{p 1} f_{p 1}-208 a_{p 2} b_{p 1} c_{p 2} f_{p 1}+$

$416 a_{p 1} b_{p 2} c_{p 2} f_{p 1}+1008 a_{p 2} c_{p 1} c_{p 2} f_{p 1}-1008 a_{p 1} c_{p 2}^{2} f_{p 1}-$

$896 a_{p 2} d_{p 1} d_{p 2} f_{p 1}+896 a_{p 1} d_{p 2}^{2} f_{p 1}-224 a_{p 2}^{2} e_{p 1} f_{p 1}+$

$224 a_{p 1} a_{p 2} e_{p 2} f_{p 1}+208 a_{p 2}^{2} f_{p 1}^{2}-112 a_{p 2} b_{p 1}^{2} f_{p 2}+$

$112 a_{p 1} b_{p 1} b_{p 2} f_{p 2}+416 a_{p 2} b_{p 1} c_{p 1} f_{p 2}-$

$208 a_{p 1} b_{p 2} c_{p 1} f_{p 2}-1008 a_{p 2} c_{p 1}^{2} f_{p 2}-208 a_{p 1} b_{p 1} c_{p 2} f_{p 2}+$

$1008 a_{p 1} c_{p 1} c_{p 2} f_{p 2}+896 a_{p 2} d_{p 1}^{2} f_{p 2}-896 a_{p 1} d_{p 1} d_{p 2} f_{p 2}+$

$224 a_{p 1} a_{p 2} e_{p 1} f_{p 2}-224 a_{p 1}^{2} e_{p 2} f_{p 2}-416 a_{p 1} a_{p 2} f_{p 1} f_{p 2}+$

$208 a_{p 1}^{2} f_{p 2}^{2}+128 a_{p 2} b_{p 2} d_{p 1} g_{p 1}-896 a_{p 2} c_{p 2} d_{p 1} g_{p 1}+$

$128 a_{p 2} b_{p 1} d_{p 2} g_{p 1}-256 a_{p 1} b_{p 2} d_{p 2} g_{p 1}-$

$896 a_{p 2} c_{p 1} d_{p 2} g_{p 1}+1792 a_{p 1} c_{p 2} d_{p 2} g_{p 1}-128 a_{p 2}^{2} g_{p 1}^{2}-$

$256 a_{p 2} b_{p 1} d_{p 1} g_{p 2}+128 a_{p 1} b_{p 2} d_{p 1} g_{p 2}+$

$1792 a_{p 2} c_{p 1} d_{p 1} g_{p 2}-896 a_{p 1} c_{p 2} d_{p 1} g_{p 2}+$

$128 a_{p 1} b_{p 1} d_{p 2} g_{p 2}-896 a_{p 1} c_{p 1} d_{p 2} g_{p 2}+$

$256 a_{p 1} a_{p 2} g_{p 1} g_{p 2}-128 a_{p 1}^{2} g_{p 2}^{2}$ 
APPENDIX B. Comparison of the absolute maximum error with available literature

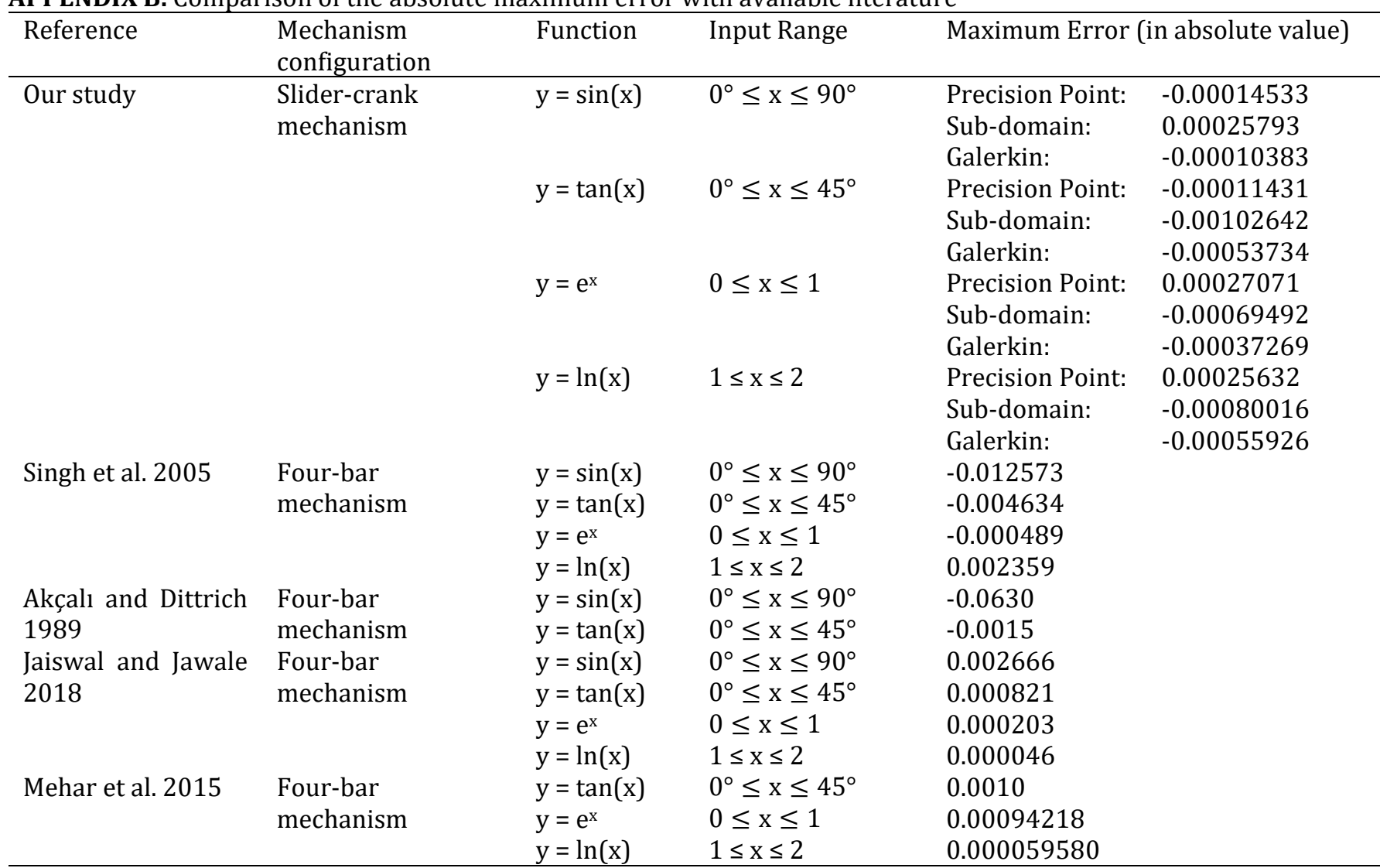

